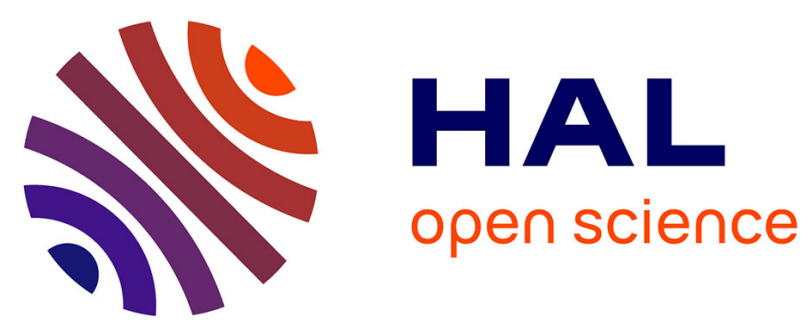

\title{
An overview of molecular events occurring in human trophoblast fusion
}

Pascale Gerbaud, Guillaume Pidoux

\section{To cite this version:}

Pascale Gerbaud, Guillaume Pidoux. An overview of molecular events occurring in human trophoblast fusion. Placenta, 2015, 36 (Suppl1), pp.S35-42. 10.1016/j.placenta.2014.12.015 . inserm-02556112v2

\section{HAL Id: inserm-02556112}

\section{https://www.hal.inserm.fr/inserm-02556112v2}

Submitted on 28 Apr 2020

HAL is a multi-disciplinary open access archive for the deposit and dissemination of scientific research documents, whether they are published or not. The documents may come from teaching and research institutions in France or abroad, or from public or private research centers.
L'archive ouverte pluridisciplinaire HAL, est destinée au dépôt et à la diffusion de documents scientifiques de niveau recherche, publiés ou non, émanant des établissements d'enseignement et de recherche français ou étrangers, des laboratoires publics ou privés. 


\section{An overview of molecular events occurring in human trophoblast fusion}

2

3

4

5

6 Running title: Trophoblast cell fusion

7 Key words: Human trophoblast, Cell fusion, Syncytins, Connexin 43, Cadherin, ZO-1, 8 cAMP-PKA signaling

9

10 Word count: 4276

11

12

13 14 15 16 17 18 19 20 21 22

\section{Pascale Gerbaud $^{1,2}$ \& Guillaume Pidoux ${ }^{1,2, \dagger}$}

${ }^{1}$ INSERM, U1139, Paris, F-75006 France; ${ }^{2}$ Université Paris Descartes, Paris F-75006; France

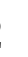

3 Corresponding author: Guillaume Pidoux, $\mathrm{PhD}$ 14 Inserm UMR-S-1139 Université Paris Descartes Faculté de Pharmacie Cell-Fusion group 75006 Paris, France Tel: +33153739602 Fax: +33144073992 E-mail: guillaume.pidoux@inserm.fr 


\section{Abstract}

24 During human placentation, mononuclear cytotrophoblasts fuse to form a multinucleated syncytia 25 ensuring hormonal production and nutrient exchanges between the maternal and fetal circulation. 26 Syncytia formation is essential for the maintenance of pregnancy and for fetal growth. The trophoblast 27 cell fusion process first requires the acquisition of cell fusion properties, then cells set up plasma 28 membrane protein macrocomplexes and fusogen machinery that trigger cell-cell fusion. Numerous 29 proteins have been shown to be directly involved in the initiation of trophoblast cell fusion. These 30 proteins must expressed at the right time and in the right place to trigger cell-cell fusion. In this 31 review, we describe the role of certain fusogenic protein macrocomplexes that form the scaffold for 32 the fusogen machinery underlying human trophoblastic-lipid mixing and merging of cell contents that 33 lead to cell fusion in physiological conditions. 


\section{Overview}

36 Cell fusion processes are essential for fertilization, fetal and placental development, skeletal muscle

37 formation and bone homeostasis [1-4]. Recently, cell fusion was also shown to play a role in 38 metastasis [5]. Cell fusion involves processes different from those involved in the fusion of vesicles to the plasma membrane, in terms of the necessary proteins, macrocomplexes and cellular signaling

40 pathways. However, the mechanical properties and biophysics of membrane lipids show certain

41 similarities. The purpose of this review is not to provide a list of all proteins and signaling pathways

42 involved in trophoblast fusion (in human primary cell cultures and cell lines), as these have already

43 been reviewed [6]. Instead, we propose to describe for the first time molecular events underlying the

44 main steps of the fusion process observed in the physiological model of cultured human primary 45 trophoblasts, as supported by biochemical and molecular biology experiments.

46 Cell fusion and syncytia formation involves the mixing of plasma membrane components and cell 47 contents between two or more cells. Two different types of cell fusion can be distinguished. In 48 homokaryon formation, during placentation, skeletal formation and bone resorption for example, 49 homotypic cells (cells of similar lineages) fuse together, while in heterokaryon formation (during 50 fertilization and metastasis for example), heterotypic cells (cells of various origins) fuse together. Cell 51 fusion processes occurring in a variety of biological contexts share many steps that are tightly regulated in space and time [7]. As described by Aguilar et al., these processes can be separated into 53 three main steps [7, 8]. The first "competence" stage involves a loss of proliferative activity, followed 54 by induction and differentiation into fusion-competent cells. The second, "commitment" stage is 55 characterized by cell migration, recognition of fusion partners and cell-cell adhesion, which initiate 56 gap junction communication leading to synchronization and exchange of fusogenic signals. This 57 triggers the organization of protein complexes necessary to promote cell-cell fusion, with apposition 58 of the outer lipid monolayers of the two cell membranes before the opening of a fusion pore and 59 progression to full fusion with mixing of cellular contents [9]. Exclusively and in some specific 60 conditions, somatic cells can remain competent for a new round of fusion, generating giant syncytia 61 and/or ensuring regeneration, as observed in muscle and placenta for instance. 
64 Human embryo implantation requires placentation, a process in which fetal cytotrophoblasts invade 65 the maternal endometrium to form an interphase with the maternal circulation, ensuring effective exchange of gases and nutrients [10]. During human implantation, the blastocyst is composed of a trophoectoderm and embryoblast. The trophoectoderm (of trophoblastic origin) undergoes intercellular fusion to generate primitive syncytia, which promote implantation of the embryo into the maternal endometrium. Two weeks after conception, villi containing cytotrophoblasts and syncytiotrophoblast appear. Throughout human pregnancy, syncytia are maintained by continuous fusion of cytotrophoblasts with overlying syncytiotrophoblasts, in a regenerative process. These multinucleated syncytia in contact with maternal blood control all feto-maternal exchanges and produce and secrete pregnancy-specific hormones $[11,12]$. The cytotrophoblast plays an essential role during human pregnancy, through its ability to differentiate into syncytia. These syncytia allow feto-maternal exchanges necessary for fetal growth. For ethical reasons, studies of primitive syncytia are not allowed in certain countries. Thus, the molecular mechanisms underlying cell fusion processes presented in this review reflect syncytial repair processes and the fusion of mononuclear cytotrophoblasts into an overlying syncytiotrophoblast.

\section{Human trophoblast fusion models}

81 The fusion process observed in the human placenta is reproducible in vitro by using purified 82 cytotrophoblasts (Fig. 1), which aggregate and then fuse to form non proliferative, multinucleated, 83 hormonally active syncytiotrophoblasts [13]. Villous explants containing the whole villous structure 84 and cell types are often used to study placental physiology. This model has the advantages of closely matching human placental physiology but is limited for intensive biochemistry and molecular biology studies. Taking this into account, and in view of our own work on human trophoblast cell fusion, we believe that human primary trophoblast culture remains the most suitable and robust model for

88 studying human trophoblast cell fusion, syncytiotrophoblast formation and regeneration. Studies of 89 primary human trophoblasts require validation of cell purity by means of immunolocalization [14].

90 Trophoblast fusion is quantified in fusion assays, where fusion indices are calculated as the ratio of the 
number of nuclei in the syncytia divided by the total number of nuclei. A syncytium is defined as at

92 least three nuclei surrounded by a cell membrane, as shown by discontinuous desmoplakin

93 immunostaining $[15,16]$. Choriocarcinoma cell lines (the trophoblast-like cell lines BeWo, JAR and

94 JEG3) are commonly used to study human placental functions. However, only BeWo cells are able to

95 fuse and form syncytia in a cAMP-driven process. Interestingly, JEG3 cells could recover a cell fusion

96 capacity under cAMP stimulation by overexpressing connexin-43 gap junction protein (Cx43) or

97 cadherin-11 $[17,18]$. We consider that BeWo cells should only be used with care to study trophoblast

98 cell fusion. Indeed, they are transformed carcinoma-like cells missing some trophoblast functions [19].

99 Moreover, BeWo cells fuse after activation of the cAMP signalling pathway. Stimulation by non

100 physiologic agents such as forskolin or cAMP analogs cause uncontrolable and profound

101 modifications of gene and protein expression, which lead directly or indirectly to fusion. Finally, a

102 recent study showed a very weak correlation between gene expression in human cytotrophoblasts and

103 BeWo cells [20]. BeWo cells thus represent a good fusion model but cannot serve as a physiologic

104 model of fusion in the human placenta.

105

106 Competence stage

107 Not all cells are fusion-competent. Competent cells commit to fusion in a space- and time-regulated 108 manner. The competence stage is the first step in the complex fusion process. Cells must first exit the 109 cell cycle, which is incompatible with cell fusion. Cytotrophoblasts purified from human placenta are 110 non proliferative [13]. A recent study showed that contacts between the syncytiotrophoblast and 111 cytotrophoblasts are necessary to maintain cytotrophoblasts in a proliferative state [21]. Methods used 112 to purify cells from human placenta probably trap competent cytotrophoblasts, due to their extraction 113 from an environment rich in hormones and other molecules with high potency for competence 114 induction, such as hCG. As observed in other models, satellite cells located close to syncytia are also 115 non proliferative until the syncytium triggers the regeneration process. The fusion-competent stage is 116 characterized by a succession of complex processes which initiate the fusion procedure, including cell 117 migration and morphological changes, and also secretion and response to extracellular signals such as 118 growth factors, cytokines and hormones. Many of these factors, of maternal, placental or fetal origin, 
119 have been reported to influence human trophoblast cell fusion: EGF/EGF-receptor (epidermal growth 120 factor; [22]), GM-CFS (granulocyte-macrophage colony-stimulating factor; [23]), LIF (leukemia 121 inhibitory factor; [24]) and PL74 (MIC-1, macrophage inhibitory cytokine 1; [25]) all promote 122 trophoblast fusion. However, the molecular mechanisms underlying trophoblast fusion induced by 123 these factors remain to be deciphered. Interestingly, we recently found that activin-A, secreted by 124 mesenchymal cells in chorionic villi, promotes fusion in a Smad-dependent manner [26], revealing the 125 first paracrine effect of mesenchymal cells inducing trophoblast syncytialization. At a certain time or 126 in a specific location, the syncytium itself controls the rate of fusion and regeneration process [21]. 127 This capacity could be acquired by sensing of the composition of the local syncytial environment 128 (chemicals, proteins and hemodynamics) and thereby exert control over cytotrophoblasts in a 129 secretion-dependent manner. In a recent a study of human placental explants, authors demonstrated 130 that, in the absence of a syncytiotrophoblast, the cytotrophoblast is non proliferative and initiates 131 intercellular fusion [21]. More experiments are needed to decipher the underlying molecular 132 mechanisms. Only TGF $\beta$ (transforming growth factor- $\beta$ ) and TNF $\alpha$ (tumor necrosis factor- $\alpha$ ) have 133 been shown to slow or inhibit human trophoblast cell fusion [27, 28]. Interestingly, TGF $\beta$ is expressed 134 by syncytiotrophoblasts, and this could support negative control of fusion by the syncytium on 135 cytotrophoblasts [29].

136 Human chorionic gonadotrophin (hCG) produced by the syncytiotrophoblast also promotes 137 syncytialization in an autocrine-paracrine manner $[15,30,31]$. Interestingly, hCG is secreted early in 138 human embryonic development by embryonic trophoblast cells and subsequently by placental 139 syncytiotrophoblast cells [32] and could serve as the trigger of primitive syncytium formation as well 140 as a positive regulator of regeneration [32]. Human CG binds to LH/CG-R (Fig. 2) and induces 141 intracellular cAMP production in trophoblasts [15, 30, 31, 33, 34]. Subsequently, cell fusion is 142 triggered by activation of protein kinase A (PKA), leading to phosphorylation and/or an increase in 143 specific gene expression of fusogenic proteins such as syncytins and also cadherin and connexin, two 144 proteins involved in the commitment stage [35-38]. In an autocrine-paracrine loop, hCG induction of 145 the cAMP signaling pathway promotes hCG production and secretion by trophoblasts [15]. In human trophoblasts, PKA phosphorylates the CREB transcription factor (cAMP Response Element-Binding 
147 Protein), which associates with CBP (CREB-binding protein) and P300 to increase the transcription of 148 competence or fusogenic genes (i.e. hCG, GCM1, Cx43 and syncytins) [39, 40]. Moreover, induction 149 of cAMP/PKA signaling activity promotes association between the transcription factors GCM1 and 150 CBP, thereby enhancing the transcription of fusogenic genes such as those encoding $\mathrm{Cx} 43$ and 151 syncytins [17, 40]. However, the first fusogenic signal (or the initiator of the competence stage) 152 remains to be identified

\section{Commitment stage}

155 The commitment stage begins right after the competence stage and is characterized by cell-cell 156 adhesion and communication processes that lead to the activation, expression, exposure or assembly of 157 the fusogenic machinery. Adherens junctions, tight junctions and gap junctions have been shown to trigger the commitment of primary cells, followed by their fusion.

161 Cadherins are transmembrane proteins involved in cell-cell adhesion by promoting the formation of 162 adherens junctions. The extracellular N-terminal domain of cadherin triggers cell-cell adhesion by 163 clustering with homotypic and heretotypic cadherins present on neighboring cells (Fig. 3). Specific 164 antibodies against the extracellular domain of E-cadherin have been shown to block human 165 trophoblast syncytialization by disrupting the aggregation of mononuclear cytotrophoblasts [35].

166 Moreover, in the same study, the authors reported that in physiologic conditions, E-cadherin protein 167 expression diminishes during cell fusion, supporting a direct role in the cellular adhesion step of the 168 commitment stage. Surprisingly, human trophoblasts treated with cadherin-11 antisense form cellular 169 aggregates but are unable to undergo terminal fusion. Contrary to E-cadherin, cadherin-11 expression 170 increases during trophoblast cell fusion [18]. These data suggest that cadherins are required for the 171 entire cell fusion process. E-cadherin mediates mononuclear cell aggregation, while cadherin-11 is 172 required for syncytialization. However, the molecular mechanisms underlying the involvement of E173 cadherin and cadherin-11 in the regulation of cell fusion remain obscure. Cadherins stabilize 174 neighboring cell membranes by anchoring them to one another and then trigger the membrane 
apposition step of the cell fusion process. This allows membrane polarization in the future region of

176 fusion and increases the probability of interaction between fusogenic proteins. Interestingly, E177 cadherin, in association with the $\beta$-catenin signaling complex, mediates the formation of adherens, 178 tight and gap junctions involved in the regulation of human trophoblast fusion [41].

- Tight junctions: zonula occludens-1 (ZO-1)

181 Zona occludens-1 (ZO-1), located on the intracellular side of the plasma membrane, belongs to the 182 MAGUK (Membrane-Associated GUanylate Kinase) family and was considered to be only a 183 component of tight junctions. However, ZO-1 was also recently described as a component of adherens 184 junctions. Tight junctions are composed of proteins that mediate the junction between the membranes of neighboring cells. In a recent study, we showed that ZO-1 is expressed in cytotrophoblasts both in vitro and in vivo and that its expression decreases during cell fusion. Interestingly, ZO-1 silencing in human trophoblasts blocks both cell fusion and cell adhesion. This lack of cell fusion is associated with a decrease in the expression of connexin-43 (Cx43), a gap junction protein [16]. These data support a role of $\mathrm{ZO}-1$ in trophoblast fusion by targeting $\mathrm{Cx} 43$ protein to the right place on the plasma membrane. Like cadherins in adherens junctions, ZO-1 permits cell-cell adhesion in the membrane apposition step and establishes gap junction communication, a prerequisite for cell fusion. A recent study showed that specific silencing of ZO-1 protein expression led to decreased E-cadherin expression [42].

196 Communication between adjacent cells is mediated through gap junctions, which are composed of 197 connexin protein $(\mathrm{Cx})$. A gap junction connects two adjacent cells through the alignment of two hemichannels, each composed of $\mathrm{Cx}$ hexamers. Gap junction channels allow the exchange of small molecules, ions, metabolites and second messengers, facilitating cellular coordination, differentiation and spatial compartmentalization [43-45]. Cx43 is the only gap junction protein expressed by human 201 cyto- and syncytiotrophoblasts lying at the interface between them [14]. Cx43 is involved in the 202 regulation of human trophoblast fusion through the control of cell-cell communication [14, 17, 46, 
203 47]. In recent silencing and reconstitution experiments, we examined the molecular mechanisms

204 underlying Cx43 involvement in the control of trophoblast fusion. We demonstrated that ezrin anchors

205 PKA to a molecular complex composed of $\mathrm{Cx} 43$ and ZO-1, and showed a direct association between

206 Cx43 and ezrin. Upon a local increase in the intracellular pool of cAMP following hCG stimulation,

207 PKA bound to ezrin activates and phosphorylates Cx43 (Fig. 4). This PKA-dependent phosphorylation

208 promotes the opening of the gap junction and allows the transfer from cell to cell of fusogenic signals

209 leading to trophoblast fusion [15]. These fusogenic signals initiate cellular synchronization, activation 210 of transcription factors (i.e. CREB, GCM1) and organization of the fusogenic macrocomplex

211 machinery in the right place and at the right time to trigger cell-cell fusion.

\section{Cell-cell fusion}

214 The last step of the fusion process is defined by the merging of the two plasma membranes and mixing 215 of cell contents. It is characterized by the formation of a fusion pore controlled in space and time. 216 Until recently, only syncytin proteins have been described to be truly fusogenic in homokaryon 217 formation. However, much remains to be understood, particularly membrane biophysics. - Syncytins: syncytin-1 and syncytin-2

The human genome contains up to $8.5 \%$ of sequences of retroviral origin, known as human 221 endogenous retroviruses (HERVs), which are composed of gag, pol and env genes [7]. In the viral 222 replicative cycle, the env gene codes for the envelope glycoprotein that mediates infection competency 223 and virus-host membrane fusion [7]. In HERV-W family, the gag and pol genes turned into 224 pseudogenes, while the env gene was domesticated to produce syncytin-1 protein [48, 49]. Syncytin-1 was the first fusogenic protein shown to control human trophoblast fusion through its retroviral envelope-like properties [50]. Syncytin-1 promotes cell fusion through its interactions with human sodium-dependent neutral amino acid transporter type 1 or 2 (hASCT1, hASCT2), which must be localized to the target-cell membrane [51]. Human ASCT2 is more highly expressed than hASCT1 in placenta, and colocalizes in vitro with $\mathrm{Cx} 43[17,52,53]$. Syncytin-2, encoded by the HERV-FRD envelope gene, is expressed in villous trophoblasts [54, 55]. Like syncytin-1, syncytin-2 mediates 
231 human trophoblast fusion through the major facilitator superfamily domain-containing 2 receptor 232 (MFSD2) [56, 57]. Although controversial, due to the use of different antibodies, syncytin-1 has been 233 detected in vitro in human trophoblasts and is maximally expressed at the cellular aggregation step $234[56,58]$, while hASCT2 is restricted to the cytotrophoblast [7]. It is generally agreed that syncytin-2 is expressed at the junction between the cyto- and syncytiotrophoblast, and syncytin-2 mRNA and 236 protein expression increase during the cell fusion process $[56,59]$. MFSD2 has been shown to be 237 expressed exclusively by the syncytiotrophoblast [57]. Pötgens et al. have proposed several models for 238 the initiation of trophoblast-membrane fusion and for how syncytin-1 and hASCT2 interconnect to 239 each other in the mononuclear cell/syncytium interphase [60]. They argue that upregulation of one or 240 both proteins (syncytin-1 and hASCT2) is sufficient and necessary to induce trophoblast cell fusion. 241 Interestingly, syncytin- $A$ and $-B$ (homologs of human syncytin-1 and -2) dual knockout mice present 242 very few syncytiotrophoblast, suggesting the existence of other fusogenic proteins [61]. Recent studies 243 of other fusion models have shown the direct role of syncytin-1 in sperm and egg fusion, osteoclast 244 fusion, and muscle formation [62, 63].

247 This part of the review will focus on the mechanisms of syncytin-1-dependent fusion mechanisms, 248 which are better characterized than those of syncytin-2. Syncytins are glycoproteins (7 N249 glycosylations for syncytin-1) composed of an intracellular domain, a transmembrane domain and an 250 extracellular domain (SU). Syncytin-1 displays a disulfide sequence, a furin cleavage site, a fusion 251 peptide and a receptor-binding domain (RBD) (Fig. 5A). Neo-synthesized syncytin-1 is glycosylated 252 in the endoplasmic reticulum (ER) and subjected to a trimerization process in which a leucine zipper253 like motif $\left(\mathrm{LX}_{6} \mathrm{LX}_{6} \mathrm{NX}_{6} \mathrm{LX}_{6} \mathrm{~L}\right)$ present in each $\mathrm{TM}$ subunit initiates oligomerization. The last 254 maturation step involves cleavage at a consensus site $\left({ }^{314-} \mathrm{RNKR}^{-317}\right)$ by cellular furin-like 255 endoproteases [7]. The two new cleaved subunits (SU and TM) are linked to each other by a disulfide 256 bond between the ${ }^{397-} \mathrm{CX}_{6} \mathrm{CC}^{-407}$ motif of the TM and the CФФC $\left({ }^{186-} \mathrm{CX}_{2} \mathrm{C}^{-189}\right)$ motif of the SU, prior 257 to expression of syncytin-1 at the cell membrane. Directional mutation of the disulfide bond impairs 258 syncytium formation in the human trophoblast [64]. The ${ }^{115-} \mathrm{SDGGGX}_{2} \mathrm{DX}_{2} \mathrm{R}^{-125}$ motif located in the 
syncytin-1-SU subunit has been characterized as the syncytin-1 receptor binding domain (RBD) for hASCT2 [64]. RBD recognition of hASCT2 induces a conformational change which leads to 261 dissociation of the SU subunit from the TM subunit by breakage of the disulfide bond (Fig. 5B). This 262 triggers a loop-to-helix movement of the syncytin-1 fusion peptide, which targets the membrane of the neighbor cell at a distance of approximately $100 \AA$, in an irreversible manner [7]. Located inside the

264 TM subunit encompassing amino acids 320 to 340 , the fusion peptide displays high hydrophobicity 265 essential for targeting the opposing cell membrane. Once fusion peptides have seeded into the target 266 membrane, the trimer initiates plasma membrane bending, merging and fusion-pore formation (Fig.

267 5B). The cytoplasmic tail of syncytin-1 is also essential for the regulation of fusion, by stabilizing the 268 trimer complex and playing a role in membrane bending [7].

- Models of membrane fusion

271 Although never demonstrated during trophoblast fusion a hemifusion intermediate is highly probable, 272 and is supported by homology with virus entry and fusion of artificial lipid bilayers. The syncytin-1 273 fusion peptide anchors the target membrane and induces local bending or a point-like protusion of the 274 membrane bilayer of the neighboring competent cell, which then establishes close proximity and/or 275 contact of the opposing cell outer membrane leaflets (Fig. 5B). Dehydration of the contact site then occurs, reducing the hydration repulsion between the opposing bilayers and outer leaflets, which form

277 a fusion stalk. The fusion stalk allows the outer lipids to mix and expands radially into a hemifusion 278 diagram (HD). The HD is characterized by the separation of the lipid contents by the still-intact inner 279 membrane. Radial expansion of the HD creates a fusion pore, triggering inner leaflet merging and cell 280 content mixing (Fig. 6). Syncytium formation leads to acquisition of highly specific functions and 281 gene and protein expression. The bending process mediated by fusogenic proteins generates local 282 changes in lipid composition by destabilizing the bilayers and facilitating lipid rearrangement prior to 283 HD and fusion pore formation. This phenomenon could explain the observed phosphatidylserine (PS) 284 flip and PS exposure on the outer membrane, considered a prerequisite for BeWo cell fusion [65]. 285 Ridell et al described PS exposure as non systematic during human trophoblast fusion but dependent on the nature of the stimuli [66]. Importantly, no leakage of cell contents into the extracellular medium 
is possible during hemifusion processes [9,67]. An alternative model of fusion has been proposed

288 with channel-like structures capable of inducing cell fusion. In this model, proteins form a hemi289 channel inside the membrane of the competent cell (as in connexin hemi-channel formation) which, 290 after connection to another hemi-channel exposed by the opposing cell, forms a fusion pore [67]. A 291 new fusion model, the stalk-hole fusion model, has recently been proposed on the basis of studies of 292 artificial lipid membranes. This model postulates the formation of an elongated stalk that expands in 293 an asymmetrical ring-like fashion. Stalk elongation promotes hole formation by destabilizing 294 membranes, thus leading to complete fusion [68]. Membrane biophysics studies of human trophoblasts 295 are needed to validate one of these models.

\section{Conclusion}

298 Trophoblast fusion and syncytiotrophoblast formation is a complex biological process essential for the 299 maintenance of pregnancy and for fetal growth. Like other cell-cell fusion models, trophoblast fusion 300 is characterized by three distinct stages: competency, commitment and cell-cell fusion. All these 301 stages are tightly regulated in space and time. Many proteins, chemicals and hormones have been 302 shown to be involved in trophoblast cell fusion. Some of the proteins considered here (fusogenic or 303 fusogenic-regulator, such as syncytins and cadherins) are also involved in other fusion models. 304 Clustering of fusogenic proteins or proteins initiating cell fusion at the right time and the right place 305 on the plasma membrane points to the existence of "fusogenic rafts". These rafts, similar to lipid rafts, 306 could help to localize fusogenic proteins and thereby ensure lipid mixing, fusion pore formation and 307 full fusion. Interestingly, the cAMP signaling pathway modulates the expression of proteins described 308 in this review and appears to play a key role in the regulation/activation of human trophoblast fusion. 309 However, more studies are needed to fully elucidate the mechanisms of trophoblast cell fusion and 310 syncytiotrophoblast regeneration, and thus the pathophysiology of human placental development. Any 311 alteration of syncytial formation and regeneration during pregnancy will affect fetal growth and the 312 outcome of the pregnancy. Anomalies of villous trophoblast differentiation and cell fusion can lead to 313 severe placental abnormalities, such as a decrease in the villous volume and surface area, both of 314 which are severely compromised in intrauterine growth restriction (IUGR) and preeclampsia [69]. 


\section{ACKNOWLEDGMENTS}

316 We thank Fatima Ferreira for technical assistance and helpful comments and input. The Cell Fusion 317 group was supported by Caisse d'Assurance Maladie des Professions Libérales Province. We thank

318 Dr. Thierry Fournier for insightful discussions. We are particularly grateful to Dr. Danièle Evain319 Brion for her support and guidance throughout the years; we will sincerely miss her advice, wisdom 320 and scientific discussions. We owe her a lot and dedicate to her this review.

321 Author contributions: GP wrote the paper and did artistic work. PG commented on the text 322 and figures; all the authors read and commented on the drafts and approved the final version.

\section{CONFLICT OF INTEREST}

325 The authors declare that they have no conflict of interest. 
327 [1] Wakelam M. The fusion of myoblasts. Biochem J. 1985;15:1-12.

328 [2] Oren-Suissa M and Podbilewicz B. Cell fusion during development. Trends Cell Biol. 2007;17(11):537-46.

[3] Midgley A, Pierce G, Denau G and Gosling J. Morphogenesis of syncytiotrophoblast in vivo: an autoradiographic demonstration. Science. 1963;141:350-1.

[4] Zambonin Zallone A, Teti A and Primavera M. Monocytes from circulating blood fuse in vitro with purified osteoclasts in primary culture. J Cell Sci. 1984;66:335-42.

[5] $\mathrm{Lu} \mathrm{X}$ and Kang $\mathrm{Y}$. Cell fusion as a hidden force in tumor progression. Cancer Res. 2009;69(22):8536-9.

[6] Huppertz B and Gauster M. Mechanisms regulating human trophoblast fusion. 2011; (Ed.) Larsson LG. pp. 203-17. Springer.

[7] Pérot P, Montgiraud C, Lavillette D and Mallet F. A comparative portrait of retroviral fusogens and syncytins. 2011; (Ed.) Larsson LI. pp. 63-115. Springer.

[8] Aguilar PS, Baylies MK, Fleissner A, Helming L, Inoue N, Podbilewicz B, Wang H and Wong M. Genetic basis of cell-cell fusion mechanisms. Trends in genetics : TIG. 2013;29(7):427-37.

[9] Chernomordik LV and Kozlov MM. Membrane hemifusion: crossing a chasm in two leaps. Cell. 2005;123(3):375-82.

[10] Benirschke K and Kaufmann P. Pathology of the human placenta. 2000; New-York.: SpringerVerlag. 22-70 pp. pp.

[11] Eaton B and Contractor S. In vitro assessment of trophoblast receptors and placental transport mechanisms. 1993; (Ed.) Redman CW, Sargent IL and Starkey PM. pp. 471-503. London: Blackwell Scientific Publication.

[12] Ogren L and Talamentes F. The placenta as an endocrine organ: polypeptides. 1994; (Ed.) Knobil E and Neill J. pp. 875-945. New-York: Raven Press.

[13] Kliman H, Nestler J, Sermasi E, Sanger J and Strauss III J. Purification, characterization , and in vitro differenciation of cytotrophoblasts from human term placentae. Endocrinology. 1986;118:1567-82.

[14] Cronier L, Defamie N, Dupays L, Theveniau-Ruissy M, Goffin F, Pointis G and Malassine A. Connexin expression and gap junctional intercellular communication in human first trimester trophoblast. Mol Hum Reprod. 2002;8(11):1005-13.

[15] Pidoux G, Gerbaud P, Dompierre J, Lygren B, Solstad T, Evain-Brion D and Tasken K. A PKAezrin-connexin 43 signaling complex controls gap junction communication and thereby trophoblast cell fusion. J Cell Sci. 2014;127(19):4172-85.

[16] Pidoux G, Gerbaud P, Gnidehou S, Grynberg M, Geneau G, Guibourdenche J, Carette D, Cronier L, Evain-Brion D, Malassine A and Frendo JL. ZO-1 is involved in trophoblastic cell differentiation in human placenta. Am J Physiol Cell Physiol. 2010;298(6):C1517-26.

[17] Dunk CE, Gellhaus A, Drewlo S, Baczyk D, Potgens AJ, Winterhager E, Kingdom JC and Lye SJ. The molecular role of connexin 43 in human trophoblast cell fusion. Biol Reprod. 2012;86(4):115.

[18] Getsios S and MacCalman CD. Cadherin-11 modulates the terminal differentiation and fusion of human trophoblastic cells in vitro. Dev Biol. 2003;257(1):41-54.

[19] King A, Thomas L and Bischof P. Cell culture models of trophoblast II: trophoblast cell lines--a workshop report. Placenta. 2000;21 Suppl A:S113-9.

[20] Bilban M, Tauber S, Haslinger P, Pollheimer J, Saleh L, Pehamberger H, Wagner O and Knofler M. Trophoblast invasion: assessment of cellular models using gene expression signatures. Placenta. 2010;31(11):989-96.

[21] Forbes K, Westwood M, Baker PN and Aplin JD. Insulin-like growth factor I and II regulate the life cycle of trophoblast in the developing human placenta. Am J Physiol Cell Physiol. 2008;294(6):C1313-22.

[22] Morrish DW, Bhardwaj D, Dabbagh LK, Marusyk H and Siy O. Epidermal growth factor induces differentiation and secretion of human chorionic gonadotropin and placental lactogen in normal human placenta. J Clin Endocrinol Metab. 1987;65(6):1282-90. 
[23] Garcia-Lloret MI, Morrish DW, Wegmann TG, Honore L, Turner AR and Guilbert LJ. Demonstration of functional cytokine-placental interactions: CSF-1 and GM-CSF stimulate human cytotrophoblast differentiation and peptide hormone secretion. Experimental cell research. 1994;214(1):46-54.

[24] Yang M, Lei ZM and Rao Ch V. The central role of human chorionic gonadotropin in the formation of human placental syncytium. Endocrinology. 2003;144(3):1108-20.

[25] Li H, Dakour J, Guilbert LJ, Winkler-Lowen B, Lyall F and Morrish DW. PL74, a novel member of the transforming growth factor-beta superfamily, is overexpressed in preeclampsia and causes apoptosis in trophoblast cells. J Clin Endocrinol Metab. 2005;90(5):3045-53.

[26] Gerbaud P, Pidoux G, Guibourdenche J, Pathirage N, Costa JM, Badet J, Frendo JL, Murthi P and Evain-Brion D. Mesenchymal activin-A overcomes defective human trisomy 21 trophoblast fusion. Endocrinology. 2011;152(12):5017-28.

[27] Morrish DW, Bhardwaj D and Paras MT. Transforming growth factor beta 1 inhibits placental differentiation and human chorionic gonadotropin and human placental lactogen secretion. Endocrinology. 1991;129(1):22-6.

[28] Leisser C, Saleh L, Haider S, Husslein H, Sonderegger S and Knofler M. Tumour necrosis factoralpha impairs chorionic gonadotrophin beta-subunit expression and cell fusion of human villous cytotrophoblast. Mol Hum Reprod. 2006;12(10):601-9.

[29] Lysiak JJ, Hunt J, Pringle GA and Lala PK. Localization of transforming growth factor beta and its natural inhibitor decorin in the human placenta and decidua throughout gestation. Placenta. 1995;16(3):221-31.

[30] Shi QJ, Lei ZM, Rao CV and Lin J. Novel role of human chorionic gonadotropin in differentiation of human cytotrophoblasts. Endocrinology. 1993;132(3):1387-95.

[31] Pidoux G, Gerbaud P, Tsatsaris V, Marpeau O, Ferreira F, Meduri G, Guibourdenche J, Badet J, Evain-Brion D and Frendo JL. Biochemical characterization and modulation of LH/CG-receptor during human trophoblast differentiation. J Cell Physiol. 2007;212(1):26-35.

[32] Seshagiri PB, Terasawa E and Hearn JP. The secretion of gonadotrophin-releasing hormone by peri-implantation embryos of the rhesus monkey: comparison with the secretion of chorionic gonadotrophin. Hum Reprod. 1994;9(7):1300-7.

[33] Keryer G, Alsat E, Tasken K and Evain-Brion D. Cyclic AMP-dependent protein kinases and human trophoblast cell differentiation in vitro. J Cell Sci. 1998;111 ( Pt 7):995-1004.

[34] Pidoux G, Gerbaud P, Marpeau O, Guibourdenche J, Ferreira F, Badet J, Evain-Brion D and Frendo JL. Human placental development is impaired by abnormal human chorionic gonadotropin signaling in trisomy 21 pregnancies. Endocrinology. 2007;148(11):5403-13.

[35] Coutifaris C, Kao LC, Sehdev HM, Chin U, Babalola GO, Blaschuk OW and Strauss JF, 3rd. Ecadherin expression during the differentiation of human trophoblasts. Development. 1991;113(3):767-77.

[36] Knerr I, Schubert SW, Wich C, Amann K, Aigner T, Vogler T, Jung R, Dotsch J, Rascher W and Hashemolhosseini S. Stimulation of GCMa and syncytin via cAMP mediated PKA signaling in human trophoblastic cells under normoxic and hypoxic conditions. FEBS Lett. 2005;579(18):3991-8.

[37] Chen CP, Chen LF, Yang SR, Chen CY, Ko CC, Chang GD and Chen H. Functional characterization of the human placental fusogenic membrane protein syncytin 2. Biol Reprod. 2008;79(5):815-23.

[38] Darrow BJ, Fast VG, Kleber AG, Beyer EC and Saffitz JE. Functional and structural assessment of intercellular communication. Increased conduction velocity and enhanced connexin expression in dibutyryl cAMP-treated cultured cardiac myocytes. Circ Res. 1996;79(2):174-83.

[39] U1 Hussain M. Transcriptional regulation of the connexin gene. 2014; (Ed.) U1 Hussain M. pp. 17-23. Springer.

[40] Chen H and Cheong ML. Syncytins: Molecular aspects. 2011; (Ed.) Larsson LG. pp. 117-37. Springer.

[41] Getsios S, Chen GT and MacCalman CD. alpha-, beta-, gamma-catenin, and p120(CTN) expression during the terminal differentiation and fusion of human mononucleate cytotrophoblasts in vitro and in vivo. Molecular reproduction and development. 2001;59(2):168-77. 
[42] Fanning AS and Anderson JM. Zonula occludens-1 and -2 are cytosolic scaffolds that regulate the assembly of cellular junctions. Annals of the New York Academy of Sciences. 2009;1165:11320.

[43] Saez JC, Berthoud VM, Moreno AP and Spray DC. Gap junctions. Multiplicity of controls in differentiated and undifferentiated cells and possible functional implications. Adv Second Messenger Phosphoprotein Res. 1993;27:163-98.

[44] Bruzzone R, White TW and Paul DL. Connections with connexins: the molecular basis of direct intercellular signaling. Eur J Biochem. 1996;238(1):1-27.

[45] Willecke K, Eiberger J, Degen J, Eckardt D, Romualdi A, Guldenagel M, Deutsch U and Sohl G. Structural and functional diversity of connexin genes in the mouse and human genome. Biol Chem. 2002;383(5):725-37.

[46] Frendo JL, Cronier L, Bertin G, Guibourdenche J, Vidaud M, Evain-Brion D and Malassine A. Involvement of connexin 43 in human trophoblast cell fusion and differentiation. J Cell Sci. 2003;116(Pt 16):3413-21.

[47] Cronier L, Frendo JL, Defamie N, Pidoux G, Bertin G, Guibourdenche J, Pointis G and Malassine A. Requirement of gap junctional intercellular communication for human villous trophoblast differentiation. Biol Reprod. 2003;69(5):1472-80.

[48] Mi S, Lee X, Li XP, Veldman GM, Finnerty H, Racie L, LaVallie E, Tang XY, Edouard P, Howes S, Keith JC and McCoy JM. Syncytin is a captive retroviral envelope protein involved in human placental morphogenesis. Nature. 2000;403(6771):785-9.

[49] Blond JL, Lavillette D, Cheynet V, Bouton O, Oriol G, Chapel-Fernandes S, Mandrand B, Mallet $\mathrm{F}$ and Cosset FL. An envelope glycoprotein of the human endogenous retrovirus HERV-W is expressed in the human placenta and fuses cells expressing the type D mammalian retrovirus receptor. Journal of virology. 2000;74(7):3321-9.

[50] Frendo JL, Olivier D, Cheynet V, Blond JL, Bouton O, Vidaud M, Rabreau M, Evain-Brion D and Mallet F. Direct involvement of HERV-W Env glycoprotein in human trophoblast cell fusion and differentiation. Mol Cell Biol. 2003;23(10):3566-74.

[51] Lavillette D, Marin M, Ruggieri A, Mallet F, Cosset FL and Kabat D. The envelope glycoprotein of human endogenous retrovirus type $\mathrm{W}$ uses a divergent family of amino acid transporters/cell surface receptors. Journal of virology. 2002;76(13):6442-52.

[52] Jansson T. Amino acid transporters in the human placenta. Pediatric research. 2001;49(2):141-7.

[53] Cariappa R, Heath-Monnig E and Smith $\mathrm{CH}$. Isoforms of amino acid transporters in placental syncytiotrophoblast: plasma membrane localization and potential role in maternal/fetal transport. Placenta. 2003;24(7):713-26.

[54] Blaise S, de Parseval N, Benit L and Heidmann T. Genomewide screening for fusogenic human endogenous retrovirus envelopes identifies syncytin 2, a gene conserved on primate evolution. Proc Natl Acad Sci U S A. 2003;100(22):13013-8.

[55] Malassine A, Frendo JL, Blaise S, Handschuh K, Gerbaud P, Tsatsaris V, Heidmann T and Evain-Brion D. Human endogenous retrovirus-FRD envelope protein (syncytin 2) expression in normal and trisomy 21-affected placenta. Retrovirology. 2008;5:6.

[56] Vargas A, Moreau J, Landry S, LeBellego F, Toufaily C, Rassart E, Lafond J and Barbeau B. Syncytin-2 plays an important role in the fusion of human trophoblast cells. J Mol Biol. 2009;392(2):301-18.

[57] Esnault C, Priet S, Ribet D, Vernochet C, Bruls T, Lavialle C, Weissenbach J and Heidmann T. A placenta-specific receptor for the fusogenic, endogenous retrovirus-derived, human syncytin-2. Proc Natl Acad Sci U S A. 2008;105(45):17532-7.

[58] Malassine A, Pidoux G, Gerbaud P, Frendo JL and Evain-Brion D. Human trophoblast in trisomy 21: a model for cell-cell fusion dynamic investigation. Adv Exp Med Biol. 2011;714:103-12.

[59] Malassine A, Blaise S, Handschuh K, Lalucque H, Dupressoir A, Evain-Brion D and Heidmann T. Expression of the fusogenic HERV-FRD Env glycoprotein (syncytin 2) in human placenta is restricted to villous cytotrophoblastic cells. Placenta. 2007;28(2-3):185-91.

[60] Potgens AJ, Drewlo S, Kokozidou M and Kaufmann P. Syncytin: the major regulator of trophoblast fusion? Recent developments and hypotheses on its action. Hum Reprod Update. 2004;10(6):487-96. 
[61] Dupressoir A, Vernochet C, Harper F, Guegan J, Dessen P, Pierron G and Heidmann T. A pair of co-opted retroviral envelope syncytin genes is required for formation of the two-layered murine placental syncytiotrophoblast. Proc Natl Acad Sci U S A. 2011;108(46):E1164-73.

[62] Bjerregaard B, Talts JF and Larsson LI. The endogenous envelope protein syncytin is involved in myoblast fusion. 2011; (Ed.) Larsson LI. pp. 267-75. Springer.

[63] Soe K, Andersen TL, Hobolt-Pedersen AS, Bjerregaard B, Larsson LI and Delaisse JM. Involvement of human endogenous retroviral syncytin-1 in human osteoclast fusion. Bone. 2011;48(4):837-46.

[64] Cheynet V, Oriol G and Mallet F. Identification of the hASCT2-binding domain of the Env ERVWE1/syncytin-1 fusogenic glycoprotein. Retrovirology. 2006;3:41.

[65] Lyden TW, Ng AK and Rote NS. Modulation of phosphatidylserine epitope expression by BeWo cells during forskolin treatment. Placenta. 1993;14(2):177-86.

[66] Riddell MR, Winkler-Lowen B, Jiang Y, Davidge ST and Guilbert LJ. Pleiotropic actions of forskolin result in phosphatidylserine exposure in primary trophoblasts. PloS one. 2013;8(12):e81273.

[67] Chernomordik LV and Kozlov MM. Mechanics of membrane fusion. Nature structural \& molecular biology. 2008;15(7):675-83.

[68] Muller M and Schick M. An alternate path for fusion and its exploration by field-theoretic means. Current topics in membranes. 2011;68:295-323.

[69] Huppertz B and Kingdom JC. Apoptosis in the trophoblast--role of apoptosis in placental morphogenesis. J Soc Gynecol Investig. 2004;11(6):353-62. 
511 Figure 1: Model of cultured villous trophobasts purified from human placenta. (left panel)

512 Schematic view of human chorionic villi. VCT for villous cytotrophoblast, ST for syncytiotrophoblast 513 and EVT for extravillous trophoblast. (Upper right panel) Model of trophoblast fusion. 514 Cytotrophoblasts (CT) aggregate after 24 to $48 \mathrm{~h}$ of culture, and fuse into a syncytiotrophoblast (ST) 515 after $72 \mathrm{~h}$. (Lower right panels) Human trophoblast stained at $24 \mathrm{~h}$ and $72 \mathrm{~h}$ of culture for desmoplakin 516 (magenta) and nuclei (DAPI, cyan). Scale bar: $15 \mu \mathrm{m}$.

Figure 2: Cyclic AMP signaling pathway activated by hCG stimulation of human trophoblasts.

519 Human chorionic gonadotropin (hCG) binds to the LH-CG receptor, a G protein-coupled receptor 520 (GPCR), which activates adenylyl cyclase in its proximity and generates pools of cAMP. Particular 521 GPCRs are confined to specific domains of the cell membrane, in association with intracellular 522 organelles or cytoskeletal constituents. The subcellular structures may harbor specific isozymes of 523 protein kinase A (PKA), that are localized in the vicinity of the receptor and the cyclase. Four 524 molecules of cAMP (red filled circles) bind to PKA regulatory subunits, which release and activate 525 PKA catalytic subunits (PKA C; yellow filled circles). The PKA C subunit phosphorylates a large 526 spectrum of targets and activates proteins or transcription factors such as CREB (cAMP response 527 element binding protein) and/or GCM1 (chorion-specific transcription factor GCMa), which promote 528 transcription activity of fusogenic genes through CBP (CREB binding protein) anchoring.

530 Figure 3: Commitment stage promoted by adherens junctions. (left panel) Representation of two 531 cells prior to the commitment stage. (right panel) Schematic depiction of the commitment stage 532 mediated though cadherin clustering. Cadherins are transmembrane proteins which ensure cell-cell 533 adhesion by the formation of adherens junctions through their extracellular N-terminal domain. The 534 intracellular domain connects the C-terminal part of cadherin to the cytoskeleton by catenin complex 535 anchoring. 
537 Figure 4: Human trophoblast gap junction. In the resting state (left panel) $\mathrm{Cx} 43$ and $\mathrm{ZO}-1$

538 compartmentalize with a pool of PKA anchored by ezrin bound to Cx43. Upon hCG stimulation (right 539 panel), cAMP increases locally and activates PKA, leading to spatiotemporally controlled 540 phosphorylation of $\mathrm{Cx} 43$ that increases communication through the gap junction and the transfer of 541 fusogenic signals. Ezrin is represented in purple; $\mathrm{Cx} 43$ in dark grey; ZO-1 in green; PKA regulatory 542 subunits in orange; PKA catalytic (C) subunits in yellow; cAMP in pink circle and phosphorylation in 543 blue circle.

545 Figure 5: Schematic depiction of trophoblast cell fusion mediated through synctin-1. (A) 546 Representation of syncytin-1 structure. SU, surface unit; TM, transmembrane unit. Syncytin-1 547 extracellular domain represented in light gray, furin cleavage site (RNKR) in red, fusion peptide 548 domain (ILPFVIGAGVLGALGTGIGGI) in purple, plasma membrane domain in green and 549 intracellular domain in blue. The $\mathrm{Y}$ indicates $\mathrm{N}$-glycosylation sites. The $\mathrm{SDGGGX}_{2} \mathrm{DX}_{2} \mathrm{R}$ motif 550 characterizes the RBD (receptor binding domain). The disulfide bond is formed between the $\mathrm{CX}_{6} \mathrm{CC}$ 551 motif of the TM domain and the СФФC motif of the SU domain. (B) Schematic depiction of syncytin5521 initiating cell fusion. a) Resting stage, b) RBD of syncytin-1 (dark grey) bound to hASCT2 (dark 553 blue), c) SU domains are removed from the trimer and release the fusion peptide (purple), d) The 554 fusion peptide harpoons the target plasma membrane, e) Plasma membrane bending is initiated.

556 Figure 6: Schematic representation of the successive stages of membrane fusion through

557 hemifusion. For simplicity, no proteins are represented in this scheme. a) Cell membrane apposition at 558 a distance of about $100 \AA$, b) Membrane bending, c) Stalk formation with mixing of cellular outer 559 lipid leaflets, d) stalk progression to hemifusion diagram (HD), e) fusion pore formation. 
Gerbaud et al, Figure 1

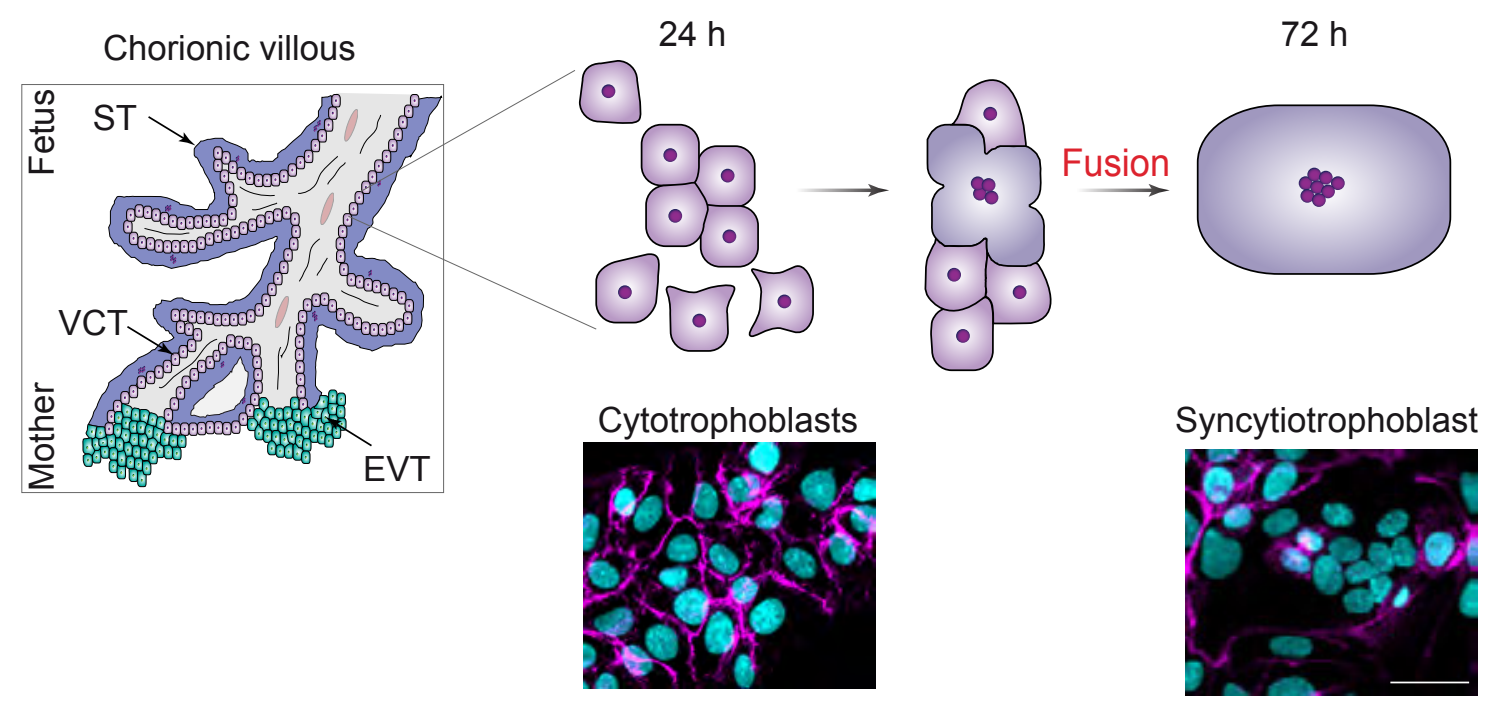


Gerbaud et al, Figure 2

hCG

Adenylyl cyclase
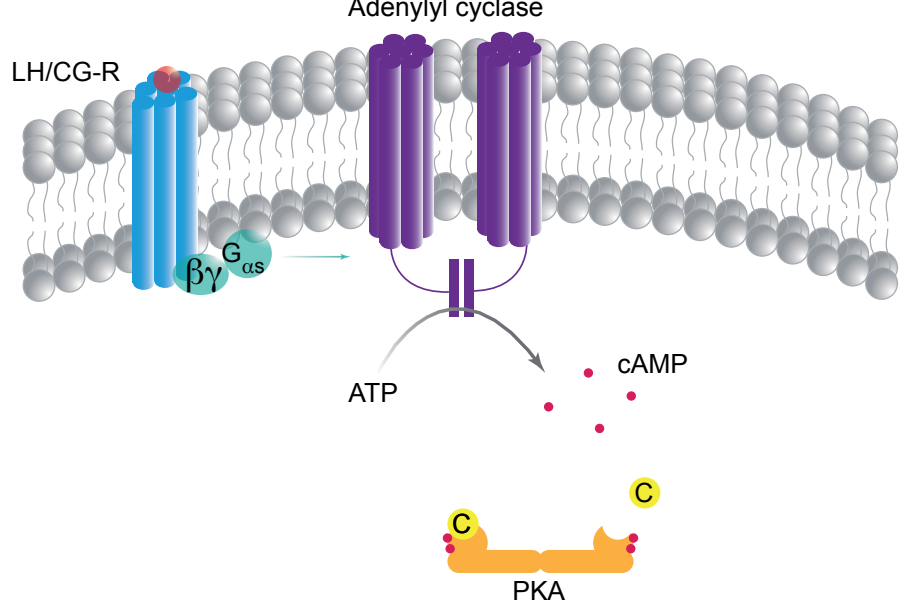

CREB GCM1

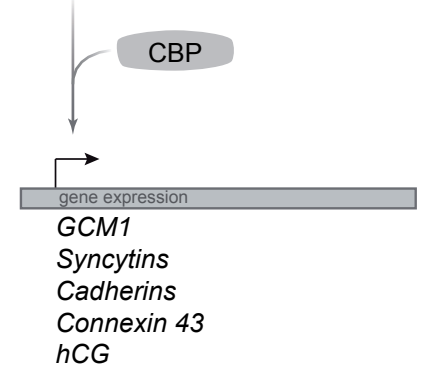




\section{Gerbaud et al, Figure 3}
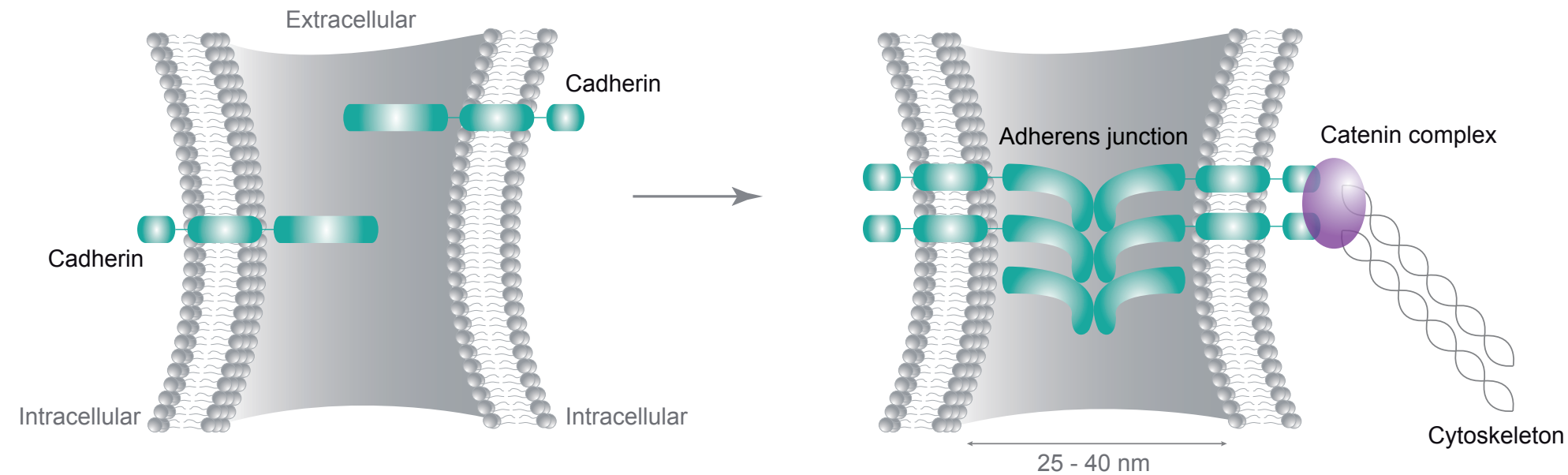


$$
\text { 䜤 }
$$




\section{Gerbaud et al, Figure 5}

A

$\stackrel{\mathrm{SDGGG} \mathrm{DX}_{2} \mathrm{R} / \mathrm{C \Phi C \Phi}}{\mathrm{SU} \text { (surface unit) }}$

B

a)

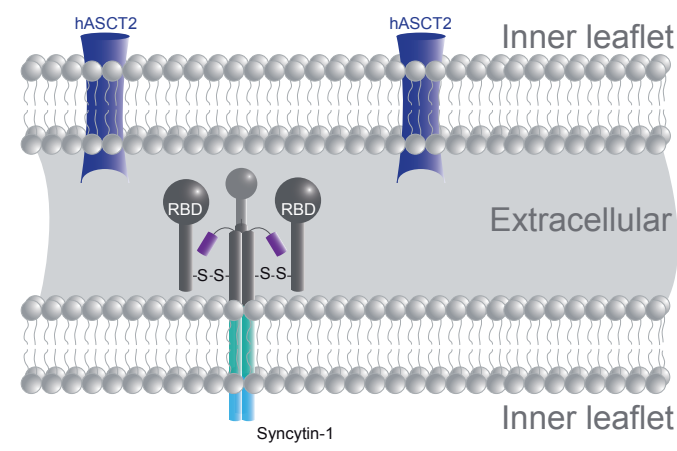

d)

e)

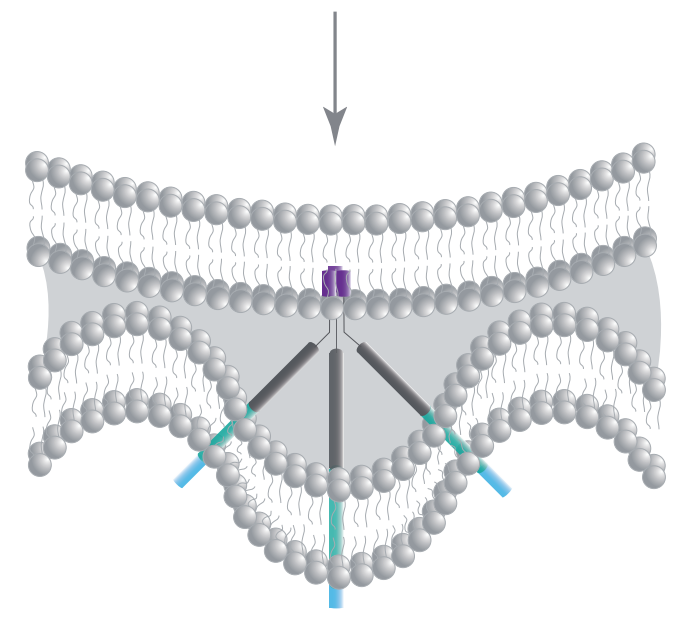

b)

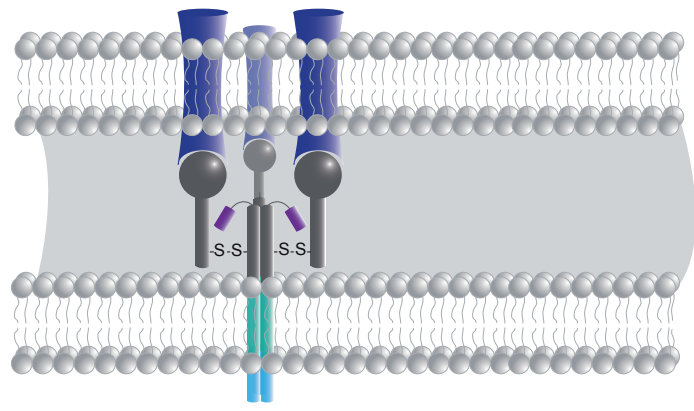

c)

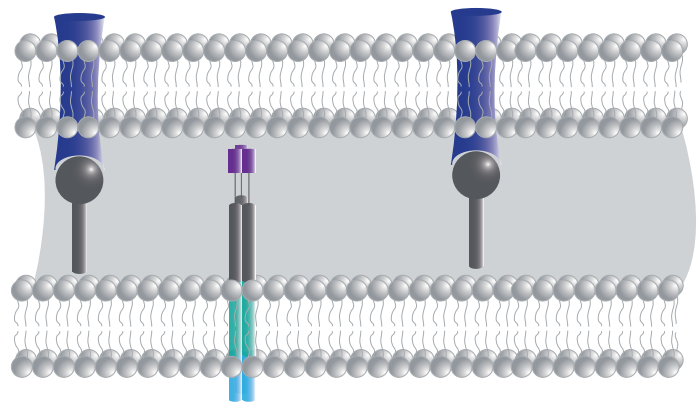




\section{Gerbaud et al, Figure 6}

a) Apposition

Inner leaflet

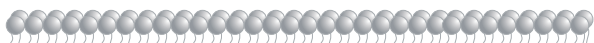

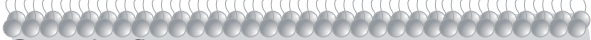

Outer leaflet

Extracellular

Outer leaflet

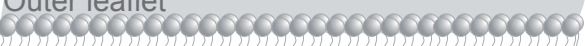

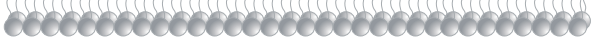

Inner leaflet

b) Bending

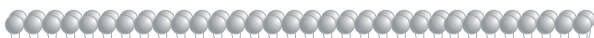

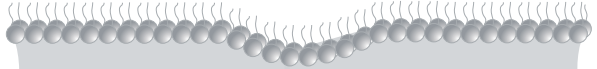

0606060606006011960606606066060

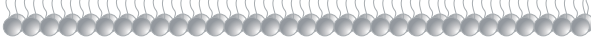

c) Stalk

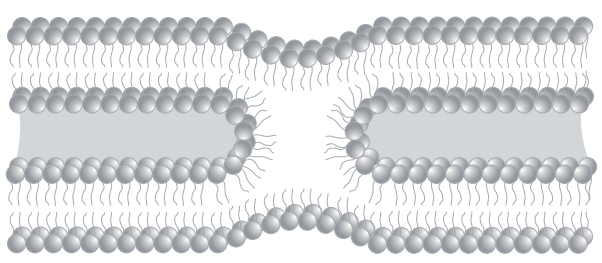

d) Hemifusion Diagram (HD)

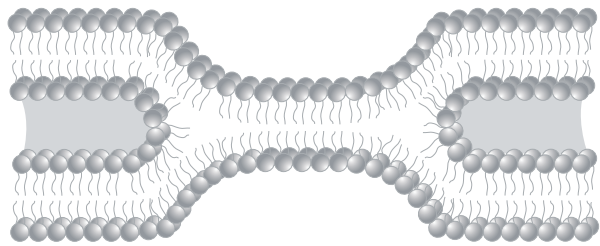

e) Fusion pore

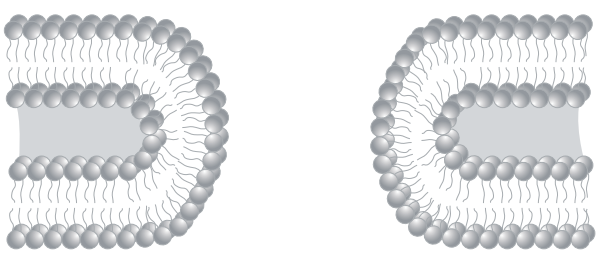

